\title{
COMMENTARY
}

\section{Sepsis and the broken endothelium}

\author{
Nathan I Shapiro*1 and William C Aird ${ }^{2}$ \\ See related research by Yang et al., http://ccforum.com/content/15/1/R11
}

\begin{abstract}
The study by Yang and colleagues examined 81 patients with septic shock due to pneumonia, along with 20 patients with pneumonia without organ dysfunction. Their major findings were that circulating levels of soluble vascular endothelial cell growth factor receptor-1 (sVEGFR-1) and urokinase-type plasminogen activator (UPA) were associated with organ dysfunction and mortality, whereas vascular endothelial cell growth factor (VEGF) levels had no such predictive power. Yang and colleagues are to be complimented for a well-conducted study of a reasonably (and helpfully!) homogeneous population of patients with sepsis that carefully and comprehensively analyzed the relationship between sVEGFR-1, UPA, VEGF and clinical outcome. The study serves not only to provide evidence in support of new diagnostic biomarker targets in sepsis, but also to augment the growing evidence of an important role of the endothelium in sepsis in general, and the VEGF signaling axis in particular.
\end{abstract}

While the exact mechanisms behind the relationship between elevated soluble vascular endothelial cell growth factor receptor-1 (sVEGFR-1) levels and clinical outcome remain controversial, the finding in the current study by Yang and colleagues [1] that sVEGFR-1 is a promising sepsis biomarker is quite consistent with previous studies $[2,3]$. In fact, in a recent investigation, we demonstrated that sVEGFR-1 performed with a diagnostic accuracy equal to, or exceeding, that of the commonly used sepsis biomarkers interleukin-6 and serum lactate [3]. Interestingly, preclinical studies have demonstrated that sepsis induces elevated levels of vascular endothelial cell growth factor (VEGF), as well as elevated levels of

\footnotetext{
*Correspondence: nshapiro@bidmc.harvard.edu

'Department of Emergency Medicine, Center for Vascular Biology Research, Beth

Israel Deaconess Medical Center, Boston, MA 02215, USA

Full list of author information is available at the end of the article
}

sVEGFR-1 [4,5]. These studies have shown that VEGF exacerbates sepsis and mediates morbidity and mortality, while it is thought that circulating sVEGFR-1 binds and neutralizes the adverse/pro-inflammatory effects of VEGF. This hypothesis is supported by the observation that supratherapeutic levels of sVEGFR-1 in murine models of sepsis deplete the blood of free VEGF and protect against morbidity and mortality.

If sVEGFR-1 is protective, then why are elevated circulating levels of sVEGFR-1 associated with worse clinical outcome in sepsis? The apparent dichotomy may be explained by one or more of the following hypotheses: 1, sVEGFR-1 levels simply reflect the vigor of the antiinflammatory response in sepsis (akin to policeman at the scene of a crime - likely the more policeman, the worse the crime); 2, elevated sVEGFR-1 may cause profound immune depression by interfering with sVEGFR-1mediated signaling in monocytes; and 3, sVEGFR-1 may interfere with endothelial repair by inhibiting VEGF signaling in endothelial cells.

As Yang and colleagues point out, the existing literature concerning circulating VEGF levels in sepsis is controversial. Previous studies have shown that adverse outcomes in sepsis are associated with either high $[2,6,7]$ or low [8] VEGF levels. In the current study, VEGF levels did not predict adverse clinical outcomes. However, it should be noted that the investigation used total VEGF levels, which is different than measuring physiologically active free or unbound VEGF. Additionally, obtaining reproducible VEGF measurements is notoriously difficult. In any event, the diagnostic value of VEGF remains circumspect. However, given the biological plausibility of a pathogenic role for VEGF in sepsis pathophysiology (by virtue of its pro-inflammatory, permeability-promoting and procoagulant effects at the level of the endothelium) we believe that the VEGF signaling axis remains a viable therapeutic target. To test this hypothesis, we are currently investigating the use of an anti-VEGF antibody in patients with septic shock (clinicaltrials.gov identifier NCT01063010).

Finally, we submit that while the exact mechanisms governing the observed association between urokinasetype plasminogen activator (uPA) and outcomes in this study is unknown, the presence of this association 
underscores the importance and dynamic role of the endothelium in sepsis. The conversion of plasminogen to plasmin, which is primarily governed by uPA, occurs at the level of the endothelium and is a primary regulator of the hemostatic balance in sepsis. As the evidence for a central role of the endothelium in sepsis builds, it is likely that a number of other endothelial-related biomarkers will emerge that reflect a 'broken endothelium' Perhaps one or more of these markers can be leveraged in future trials to guide therapy with novel yet-to-be-determined endothelium-sparing agents.

\section{Abbreviations}

sVEGFR-1, soluble vascular endothelial cell growth factor receptor-1; uPA urokinase-type plasminogen activator; VEGF, vascular endothelial cell growth factor.

\section{Competing interests}

The authors declare that they have no competing interests.

\section{Author details}

'Department of Emergency Medicine, Center for Vascular Biology Research, Beth Israel Deaconess Medical Center, Boston, MA 02215, USA. 'Department of Medicine, Center for Vascular Biology Research, Beth Israel Deaconess Medical Center, Boston, MA 02215, USA.

Published: 21 March 2011

\section{References}

1. Yang KY, Liu KT, Chen YC, Chen CS, Lee YC, Perng RP, Feng JY: Plasma soluble vascular endothelial growth factor receptor-1 levels predict outcomes of pneumonia-related septic shock patients: a prospective observational study. Crit Care 2011, 15:R11.

2. Shapiro NI, Yano K, Okada H, Fischer C, Howell M, Spokes KC, Ngo L, Angus DC, Aird WC: A prospective, observational study of soluble FLT-1 and vascular endothelial growth factor in sepsis. Shock 2008, 29:452-457.

3. Shapiro NI, Schuetz P, Yano K, Sorasaki M, Parikh SM, Jones AE, Trzeciak S, Ngo L, Aird WC: The association of endothelial cell signaling, severity of illness, and organ dysfunction in sepsis. Crit Care 2010, 14:R182.

4. Yano K, Liaw PC, Mullington JM, Shih SC, Okada H, Bodyak N, Kang PM, Toltl L, Belikoff B, Buras J, Simms BT, Mizgerd JP, Carmeliet P, Karumanchi SA, Aird WC Vascular endothelial growth factor is an important determinant of sepsis morbidity and mortality. J Exp Med 2006, 203:1447-1458.

5. Tsao PN, Chan FT, Wei SC, Hsieh WS, Chou HC, Su YN, Chen CY, Hsu WM, Hsieh FJ, Hsu SM: Soluble vascular endothelial growth factor receptor-1 protects mice in sepsis. Crit Care Med 2007, 35:1955-1960.

6. Pickkers P, Sprong T, Eijk LV, Hoeven HV, Smits P, Deuren MV: Vascular endothelial growth factor is increased during the first 48 hours of human septic shock and correlates with vascular permeability. Shock 2005, 24:508-512.

7. van der Flier M, van Leeuwen HJ, van Kessel KP, Kimpen JL, Hoepelman Al, Geelen SP: Plasma vascular endothelial growth factor in severe sepsis. Shock 2005, 23:35-38.

8. Mankhambo LA, Banda DL; IPD Study Group, Jeffers G, White SA, Balmer P, Nkhoma S, Phiri H, Molyneux EM, Hart CA, Molyneux ME, Heyderman RS, Carrol ED: The role of angiogenic factors in predicting clinical outcome in severe bacterial infection in Malawian children. Crit Care 2010, 14:R91.

doi:10.1186/cc10044

Cite this article as: Shapiro NI, Aird WC: Sepsis and the broken endothelium. Critical Care 2011, 15:135. 